Research Article

\title{
Stepwise Improvement for Environmental Performance of Transportation Industry in China: A DEA Approach Based on Closest Targets
}

\author{
Jiawei Li $\mathbb{D}$, Qingbo Huang $(\mathbb{D}$, and Yan Li $\mathbb{D}$ \\ School of Maritime Economics and Management, Dalian Maritime University, Dalian 116026, Liaoning, China \\ Correspondence should be addressed to Qingbo Huang; huangqingbo@dlmu.edu.cn
}

Received 28 October 2020; Revised 27 February 2021; Accepted 11 March 2021; Published 25 March 2021

Academic Editor: Taseer Muhammad

Copyright ( 2021 Jiawei Li et al. This is an open access article distributed under the Creative Commons Attribution License, which permits unrestricted use, distribution, and reproduction in any medium, provided the original work is properly cited.

\begin{abstract}
Transportation is regarded as an industry with high energy consumption and high $\mathrm{CO}_{2}$ emissions. Little attention has been paid to the environmental performance improvement of China's transportation industry, especially in a stepwise improvement way. In this study, we first apply the closest targets DEA method to evaluate the environmental performance in the transportation industry of 30 provincial-level regions in China's mainland from 2010 to 2017. Then, we incorporate the closest targets and contextdependent DEA model and thus conform a stepwise projection path for each inefficient province to improve environmental performance with less effort by the way of identifying a sequence of intermediate closest targets. The empirical study shows that the environmental performance of the transportation industry obtained from the closest targets model is greater than that obtained from the SBM model for each province. Among the three areas, the eastern area performs the best in environmental performance followed by the central region and western region. Shanghai has the best environmental performance. Additionally, compared with conventional DEA models, the proposed stepwise improvement method can generate easier and closer achieved targets for the inefficient provinces. Hainan, Yunnan, and Xinjiang provinces have the lowest environmental performance, which need four steps to achieve efficiency.
\end{abstract}

\section{Introduction}

With the benefit from the "reform and opening up" launched in 1978, China's economy has rapidly improved. China's GDP (gross domestic product) increased from 0.37 trillion yuan in 1978 to 90.03 trillion yuan in 2018 , with an average growth rate of $9.4 \%$ [1]. However, the rapid economic growth has brought about problems of huge energy consumption and pollution emissions (e.g., $\mathrm{CO}_{2}$ emissions) [2, 3]. In 2018, the total energy consumption of China reached 4.64 billion tons of standard coal equivalent (tce), 7.7 times that of 1978, ranking first in the world [4]. The transportation industry has been the third-largest energy consumer industry in China [5], and it has become one of China's main sources of $\mathrm{CO}_{2}$ emissions $[6,7]$. With the rapid development of the transportation industry, the energy consumption and $\mathrm{CO}_{2}$ emissions of the transportation industry will continue to grow [8]. In 2050, the energy consumption of China's transportation industry would increase to 636 million tons of oil equivalent and produce 16.02 billion tons of $\mathrm{CO}_{2}$ [9]. Hence, it is of great importance to effectively assess the environmental performance of the transportation industry in China. By doing this, it may provide helpful information to decision-makers to achieve a balance between economic growth and sustainable development and finally to improve environmental performance.

To properly evaluate the environmental performance of the transportation industry, many scholars have proposed approaches based on data envelopment analysis (DEA) $[10,11]$. DEA, which was first proposed by Charnes et al. [12], has been extensively used to evaluate the relative performance of a set of homogeneous decisionmaking units (DMUs) which consume multiple inputs to 
produce multiple outputs $[13,14]$. In addition to evaluating performance, DEA can also provide benchmarking information or targets to guide inefficient DMUs to improve their performance $[15,16]$. Given its advantages, DEA has been applied as an analytical technique in the fields of agriculture, banking, transportation, supply chain, and others [17]. Thus, we suggest the use of the DEA methodology as the main tool to measure the environmental performance of the transportation industry in China's mainland.

Various DEA models have been applied to the environmental performance evaluation of China's transportation industry (see [18-22]). However, the studies on the environmental performance improvement of the transportation industry are largely lacking. On the other hand, prior research applying DEA approaches usually yields a "furthest" target or benchmark for any inefficient DMU. Under such circumstances, it is difficult for the inefficient DMU to achieve efficiency along the direction determined by its "furthest" target or benchmark in a single step because of the large difference in the inputs and/or outputs between it and the targets. To avoid this problem, one effective way is to find the closest targets for the inefficient DMU. The closest targets have values for inputs and/or outputs similar to the current values of the inefficient DMU; thus, it can achieve such targets with less effort $[15,23]$. However, when there is a large performance gap between the inefficient DMU and its corresponding closest target, it is still hard for such inefficient DMU to achieve the closest targets in a single step or in a short time [24].

To fill the gaps in the prior literature, this paper proposes a new stepwise improvement method that incorporates closest targets and context-dependent DEA model. In contrast to the traditional DEA models (e.g., SBM) that yield the "furthest" targets for the inefficient DMUs, the proposed approach in this study generates the closest targets that have the inputs and outputs similar to the assessed inefficient DMUs, which means that the inefficient DMUs can improve to the efficient frontier with less effort along the direction to the corresponding closest targets. In particular, to help an inefficient DMU that is far away from its closest targets achieve efficiency, our approach provides a stepwise improvement path that consists of several intermediate closest targets on different levels of efficient frontier identified by the context-dependent DEA approach, thus ensuring the inefficient DMU improve to the efficient frontier by following this path.

The rest of the paper is organized as follows. The following section reviews the literature on environmental performance evaluation of the transportation industry based on DEA methods and the closest targets approaches in DEA. In Section 3, we provide the preliminaries of relevant DEA models. The stepwise improvement approach that incorporates the closest targets and contextdependent DEA model is proposed in Section 4. In Section 5 , we apply our approach to the transportation industry at provincial administrative regions in mainland China. The last section gives the conclusion and several possible research directions.

\section{Literature Review}

2.1. Environmental Performance Evaluation of Transportation Industry. Considering the importance of reducing $\mathrm{CO}_{2}$ emissions and energy consumption, a large body of the literature has used DEA methods to evaluate the environmental performance of transport sectors. Egilmez and Park [25] integrated EIO-LCA and DEA to access the environmental performance of the U.S. transportation industry. Beltrán-Esteve and Picazo-Tadeo [26] used a directional distance function approach to measure the environmental performance changes in the transportation industry of 38 countries/regions from 1995 to 2009. They found that the improvement of environmental performance is mainly driven by eco-innovation. Park et al. [11] applied a nonradial SBM-DEA model to evaluate the environmental efficiency and potential $\mathrm{CO}_{2}$ reduction of the transportation sectors in the U.S. from years 2004 to 2012. Their findings revealed that the transportation sectors in the U.S. were environmentally inefficient with an average environmental efficiency score below 0.64. Mavi et al. [27] applied a common set of weights double frontier DEA-based Malmquist productivity index method to track the changes of the environmental performance of the transportation industry in Iran. The results indicated that the environmental performance of the transportation industry in Iran had a constant or declining trend from 2014 to 2017. Omrani et al. [28] used a DEAcooperative game approach to evaluate the energy efficiency in transportation sector at the provincial level in Iran. They found that smaller provinces have higher energy efficiency.

In recent years, transportation industry has become one of the industries with high energy consumption and high $\mathrm{CO}_{2}$ emissions in China, and the environmental performance evaluation of China's transportation industry has received widespread attention. Chang et al. [10] used a nonradial SBM model to analyze the environmental efficiency of China's transportation sectors at the provincial regional level. Their results showed that the environmental efficiency of China's transportation industry is very low, and the environmental efficiencies of most provinces are below $50 \%$ of the target level. Cui and Li [29] employed a threestage virtual frontier DEA model to evaluate energy efficiencies in the transportation industry of 30 Chinese provincial administrative regions. They found that structure and management measures have impacts on transportation energy performance. Wu et al. [18] measured the energy and environmental performance of transportation systems at the provincial level in China based on a parallel DEA approach. The result showed that there are large efficiency differences between the passenger and freight transportation subsystems. Stefaniec et al. [30] proposed a triple bottom linebased network DEA approach to evaluate the environmental performance of inland transportation in China. The results indicated that the overall efficiency of the transportation industry shows an upward trend. Zhu et al. [31] developed a new equilibrium efficient frontier DEA approach to assess the environmental performance of transportation sectors in China under the constraints of energy consumption and environmental pollutions. The findings revealed that there 
exist large disparities in environmental performance among regions. Also, some scholars have paid attention to the environmental performance of the transportation industry focusing one region; for example, Tian et al. [32] utilized an improved super-efficiency SBM-DEA model to measure the sustainable development of the transportation industry in Shaanxi province.

Besides, there are some scholars who analyzed the environmental performance of transportation subsectors, such as the railroad sectors $[33,34]$, the airport transportation [35-38], the land transportation [22,39], and ports [20, 40].

2.2. Closest Targets Approach in DEA. Finding the closest targets for inefficient DMUs to help them achieve efficiency with less effort has been a hot issue in the DEA area. In DEA research on finding closest targets, two primary ways have attracted attention. One way is to identify all efficient facets, calculate the least distance from the inefficient DMU to each efficient facet, and finally choose the minimum distance from these least distances. This type of method originated from Briec [41], who used the Hölder distance function to determine the least distance, and Frei and Harker [42], who used the Euclidean distance to the Pareto-efficient frontier to obtain the closest targets or benchmarks. Later, weighted Euclidean distance approaches were proposed by Amirteimoori and Kordrostami [43] and Aparicio and Pastor [44], among others. The other way is to find the closest targets for a certain inefficient DMU based on similarity criteria is an approach based originally on the mixed-integer linear program proposed by Aparicio et al. [15], which can obtain the closest target on the Pareto-efficient frontier for a given inefficient DMU. In line with Aparicio et al. [15], Pastor and Aparicio [45], Ando et al. [46], Aparicio and Pastor [47], and Fukuyama et al. [48], the properties of such methodologies were further improved (see [49] for a detailed discussion).

In addition to the research on property improvement, the closest targets approach has also been applied to various areas. An et al. [50] used the closest targets model based on the enhanced Russell measure to evaluate the environmental performance of 20 thermal power enterprises in Anhui province of China. By using the closest targets method, Li et al. [20] provided benchmarking information for primary freight transportation seaports in China to improve their environmental performance. Wu et al. [19] incorporated the closest targets technique into carbon emissions abatement allocation and applied it for carbon emissions abatement target setting and allocation for 20 APEC economies. Razipour-GhalehJough et al. [51] proposed a closest targets model in the presence of weight restrictions to evaluate and improve the efficiency of Iranian banks.

In reviewing the above discussed literature, we find that although various DEA models have been used in the environmental performance evaluation of the transportation industry, the studies on the environmental performance improvement of the transportation industry are largely requiring. Additionally, prior research applying DEA approaches usually yields a "furthest" target or benchmark for the inefficient DMU. As a result, it is difficult for the inefficient DMU to achieve efficiency along the direction determined by its "furthest" target or benchmark in a single step because of the large difference in the inputs and outputs between it and the targets. Therefore, in this study, we incorporate closest targets and context-dependent DEA model and thus conform a stepwise projection path for each inefficient province to improve environmental performance with less effort by the way of identifying a sequence of intermediate closest targets.

\section{Preliminaries}

3.1. Slacks-Based Measure (SBM) considering Undesirable Outputs. Suppose that there are $n$ DMUs, and each $D M U_{j}(j=1,2, \cdots, n)$ consumes $m$ inputs to produce $s$ desirable outputs accompanied by $h$ undesirable outputs. Variables $x_{i j}(i=1,2, \cdots, m), \quad y_{r j}(r=1,2, \cdots, s)$, and $z_{q j}(q=1,2, \cdots, h)$ represent the $i$-th input, $r$-th desirable output, and $q$-th undesirable output of $D M U_{j}(j=1,2, \cdots, n)$, respectively. The production possibility set which is constructed by these $n$ DMUs is defined as follows $[52,53]$ :

$$
T=\left\{\begin{array}{l|l}
(x, y, z) \mid \begin{array}{ll}
\sum_{j=1}^{n} \lambda_{j} x_{i j} \leq x_{i}, & i=1,2, \cdots, m \\
\sum_{j=1}^{n} \lambda_{j} y_{r j} \geq y_{r}, & r=1,2, \cdots, s, \\
\sum_{j=1}^{n} \lambda_{j} z_{q j}=z_{q}, \quad q=1,2, \cdots, h, \lambda_{j} \geq 0, j=1,2, \cdots, n
\end{array}
\end{array}\right\} .
$$

Given an evaluated $D M U_{k}$, the following linear program, namely, nonradial and nonoriented slacksbased measure (SBM) based on production possibility set
(1) can be used to measure its relative environmental efficiency [54-57]. Because the SBM model encompasses the excesses of inputs and undesirable outputs and the 
shortfalls of desirable outputs simultaneously, this technique has been widely used in environmental performance evaluation:

$$
\begin{aligned}
& \rho=\min \frac{1-(1 / m) \sum_{i=1}^{m} s_{i k}^{-} / x_{i k}}{1+(1 /(s+h))\left(\sum_{r=1}^{s} s_{r k}^{+} / y_{r k}+\sum_{q=1}^{h} s_{q k}^{-} / z_{q k}\right)}, \\
& \text { s.t. } \sum_{j=1}^{n} \lambda_{j} x_{i j}+s_{i}^{-}=x_{i k}, \quad i=1,2, \cdots, m, \\
& \sum_{j=1}^{n} \lambda_{j} y_{r j}-s_{r}^{+}=y_{r k}, \quad r=1,2, \cdots, s, \\
& \sum_{j=1}^{n} \lambda_{j} z_{q j}+s_{q}^{-}=z_{q k}, \quad q=1,2, \cdots, h, \\
& \lambda_{j} \geq 0, \quad j=1,2, \cdots, n, \\
& s_{i}^{-}, s_{r}^{+}, s_{q}^{-} \geq 0, \quad \forall i, r, q .
\end{aligned}
$$

In model (2), $\theta$ measures the relative environmental efficiency of $D M U_{k}$; it ranges from 0 to 1, i.e., the higher value of $\theta$ is, the better environmental efficiency $D M U_{k}$ achieves. $s_{i}^{-}$and $s_{q}^{-}$, respectively, represent the potential reductions of $i$-th input and $q$-th undesirable output, while $s_{r}^{+}$indicates the potential expansion of $r$-th desirable output [54]. Additionally, $\lambda_{j}(j=1,2, \cdots, n)$ are intensity variables which connect inputs and outputs. Denoting the optimal solution of model (2) for $D M U_{k}$ by $\left(\theta^{*}, s_{i}^{-*}, s_{r}^{+*}, s_{q}^{-*}, \lambda_{j}^{*}\right)$, we have the following two remarks.

Remark 1. $D M U_{k}$ is strongly efficient if and only if $\theta^{*}=1$, and $s_{i}^{-*}=s_{r}^{+*}=s_{q}^{-*}=0, \forall i, r, q . D M U_{k}$ is weakly efficient if and only if $\theta^{*}=1$ and $s_{i}^{-*} \neq 0, s_{r}^{+*} \neq 0$, and $s_{q}^{-*} \neq 0$ for some inputs and outputs.

Remark 2. $\theta^{*}<1$ means $D M U_{k}$ is inefficient, and the target on the efficient frontier can be calculated by $\widehat{x}_{i k}=x_{i k}-s_{i k}^{-*}$, $\hat{y}_{r k}=y_{r k}+s_{r k}^{+*}$, and $\widehat{z}_{q k}=z_{q k}-s_{q k}^{-*}$.

\subsection{Closest Targets Model considering Undesirable Outputs.} To help the inefficient DMUs become efficient with the least effort (minimizing the contraction of inputs and/or augmentation of outputs), the closest target and minimum distance to the Pareto-efficient frontier approach have been proposed and investigated by many scholars (see Aparicio et al. [49] for details). Denoting $E$ as the set of strongly efficient units, Aparicio et al. [15] constructed the following strongly efficient frontier without considering undesirable outputs under the assumption of constant returns to scale (CRS):

$$
\mathrm{SE}=\left\{\begin{array}{l|l}
\left(x_{i}, y_{r}\right) & \begin{array}{l}
\sum_{j \in E} \lambda_{j} x_{i j}=x_{i}, \quad i=1,2, \cdots, m, \\
\sum_{j \in E} \lambda_{j} y_{r j}=y_{r}, \quad r=1,2, \cdots, s, \\
\sum_{r=1}^{s} u_{r} y_{r j}-\sum_{i=1}^{m} w_{i} x_{i j}+\varphi_{j}=0, \quad \forall j \in E, \\
\varphi_{j} \leq M b_{j}, \quad \forall j \in E, \\
\lambda_{j} \leq M\left(1-b_{j}\right), \quad \forall j \in E, \\
b_{j} \in\{0,1\}, \quad \forall j \in E, \\
\varphi_{j} \geq 0, \quad \forall j \in E, \\
\lambda_{j} \geq 0, \quad \forall j \in E, \\
w_{i}, u_{r} \geq 1, \quad \forall i, r
\end{array}
\end{array}\right\},
$$

where $M$ is a large non-negative constant. The first two constraints ensure that each DMU in $T$ is a linear combination of strongly efficient DMUs. Constraints $\sum_{r=1}^{s} u_{r} y_{r j}-\sum_{i=1}^{m} w_{i} x_{i j}+\varphi_{j}=0, \forall j \in E$, and $w_{i}, u_{r} \geq 1, \forall i, r$ construct the hyperplanes that the units belonging to the production possibility set either lie on or away from. If $\lambda_{j}>0$, that is, $b_{j}=0$ and $\varphi_{j}=0, \forall j \in E$, then $D M U_{j}$ is a peer for other DMUs.

Considering the undesirable outputs, the following model is proposed to evaluate the environmental efficiencies for the inefficient DMUs on the basis of (3). The evaluated inefficient $\mathrm{DMU}$ is denoted as $D M U_{p}$.

$$
\begin{aligned}
\rho= & \max \frac{1-(1 / m) \sum_{i=1}^{m} s_{i p}^{-} / x_{i p}}{1+(1 / s+h)\left(\sum_{r=1}^{s} s_{r p}^{+} / y_{r p}+\sum_{q=1}^{h} s_{q p}^{-} / z_{q p}\right)}, \\
\text { s.t. } & \sum_{j \in E} \lambda_{j} x_{i j}=x_{i p}-s_{i p}^{-}, \quad i=1,2, \cdots, m, \\
& \sum_{j \in E} \lambda_{j} y_{r j}=y_{r p}+s_{r p}^{+}, \quad r=1,2, \cdots, s, \\
& \sum_{j \in E} \lambda_{j} z_{q j}=z_{q p}-s_{q p}^{-}, \quad q=1,2, \cdots, h, \\
& \sum_{r=1}^{s} u_{r} y_{r j}-\sum_{i=1}^{m} w_{i} x_{i j}-\sum_{q=1}^{h} v_{q} z_{q j}+\varphi_{j}=0, \quad \forall j \in E, \\
& \varphi_{j} \leq M b_{j}, \quad \forall j \in E, \\
& \lambda_{j} \leq M\left(1-b_{j}\right), \quad \forall j \in E, \\
& \varphi_{j} \geq 0, \quad \forall j \in E, \\
& \lambda_{j} \geq 0, \quad \forall j \in E, \\
& b_{j} \in\{0,1\}, \quad \forall j \in E, \\
& s_{i p}^{-}, s_{r p}^{+}, s_{q p}^{-} \geq 0, \quad \forall i, r, q, \\
& w_{i}, u_{r}, v_{q} \geq 1, \quad \forall i, r, q .
\end{aligned}
$$


In model (4), the maximization of the objective function helps the decision-makers discover the closest targets for inefficient $D M U_{p}$. The optimal solution of model (4) is denoted as $\left(\rho^{*}, \lambda_{j}^{*}, s_{i p}^{-*}, s_{r p}^{+*}, w_{i}^{*}, u_{r}^{*}, \varphi_{j}^{*}, b_{j}^{*}, \forall i, r, j\right)$, and $D M U_{p}$ can achieve the closest target on the efficient frontier by $\hat{x}_{i p}=x_{i p}-s_{i p}^{-*}, \hat{y}_{r p}=y_{r p}+s_{r p}^{+*}$, and $\widehat{z}_{q p}=z_{q p}-s_{q p}^{-*}$.

Compared with the target obtained from a conventional DEA model, such as the SBM mentioned above, model (4) generates a closest Pareto-efficient target on the efficient frontier for any inefficient DMU. Such closest targets are as similar as possible to the evaluated DMUs' observed inputs and outputs. Therefore, each inefficient DMU can improve its performance by moving toward efficiency along the direction to its closest target with less effort than along the projection direction used in the SBM model.

Figure 1 clearly illustrates the SBM projection and closest target projection.

\section{Stepwise Improvement Based on Closest Targets in DEA}

4.1. The Context-Dependent Model. Seiford and Zhu [58] developed a context-dependent DEA model to divide all assessed DMUs into different efficient frontiers, where the DMUs located on the same frontier have similar performance. Thus, an inefficient DMU can improve to be efficient by step projection.

Denoting $J^{1}=\left\{D M U_{j}, j=1,2, \cdots, n\right\}$ as the set of all assessed DMUs, $J^{d+1}=J^{d^{j}}-E^{d}$, where $E^{d}$ is the set of all efficient DMUs in the $d$-th efficient frontier. In other words, $E^{d}=\left\{D M U_{k} \in J^{d} \mid \theta_{k}^{d *}=1\right\}$ where $\theta_{k}^{d *}$ is the optimal efficiency yielded by the DEA model (e.g., CCR and SBM). When $d=1$, all efficient DMUs in $E^{1}$ form the first-level efficient frontier. When $d=2$, all efficient DMUs in $E^{1}$ are eliminated, the remaining DMUs construct $J^{2}$, and the efficient DMUs in $J^{2}$ compose the set $E^{2}$. Continuing this, all the different levels of efficient frontiers are identified. The following steps proposed by Seiford and Zhu [58] are applied to obtain such frontiers:

(i) Step 1. Assess all DMUs in $J^{1}$ by the DEA model to identify the efficient DMUs which compose $E^{1}$. The efficient DMUs in $E^{1}$ construct the first-level efficient frontier.

(ii) Step 2. Eliminate the efficient DMUs in $E^{1}$. Reevaluate the residual DMUs in $J^{2}$ and identify the efficient DMUs which compose $E^{2}$. The efficient DMUs in $E^{2}$ construct the second-level efficient frontier. In other words, the efficient DMUs in the previous level are always removed from the current evaluation; that is, $J^{d+1}=J^{d}-E^{d}$.

(iii) Step 3. Repeat step 2 until $J^{d+1}=\varnothing$.

Figure 2 clearly illustrates the concept of the contextdependent DEA model introduced by Seiford and Zhu [58], in which four levels of efficient frontier are exhibited.

4.2. Stepwise-Closest Targets Model. Model (4) can help the inefficient DMUs to improve to the Pareto-efficient frontier

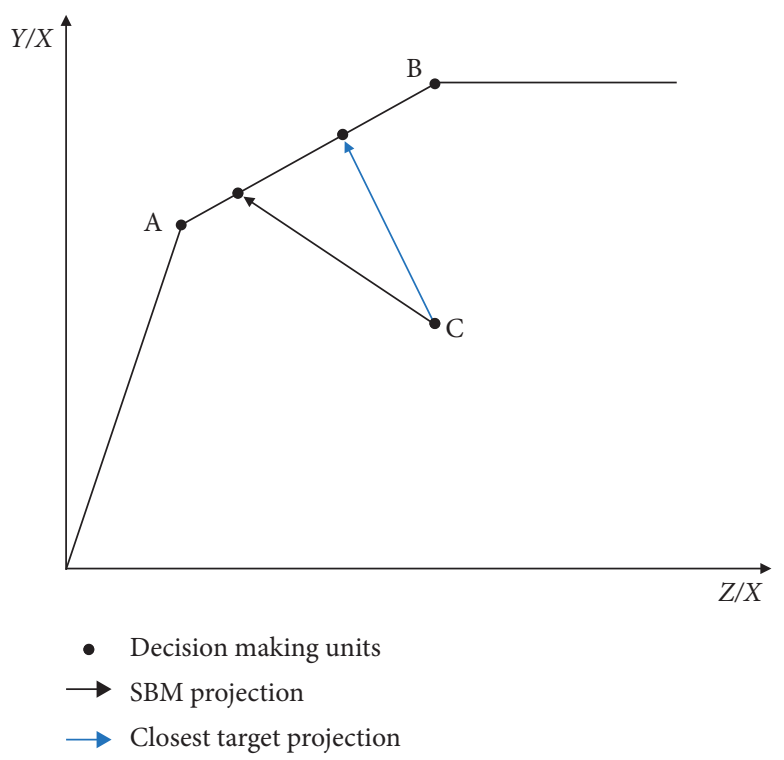

FIGURE 1: Closest target projection and SBM projection.

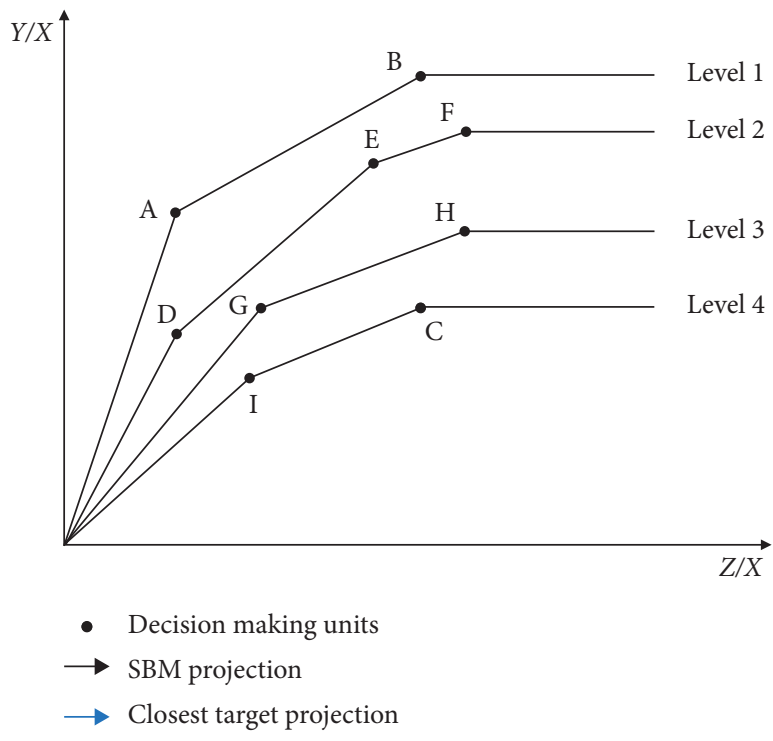

Figure 2: Different levels of the efficient frontier.

with less effort than conventional DEA models. When an inefficient $\mathrm{DMU}$ is far away from the efficient frontier, it may be hard to improve to be efficient in one step because of its current limited technology. In this section, we propose the stepwise-closest targets model which incorporates the closest targets and the context-dependent DEA model to seek a stepwise improvement path for the inefficient DMUs, as illustrated in Figure 3.

The distinct advantage of the stepwise-closest targets model is that it generates several intermediate closest targets thus helping the inefficient DMUs, especially the inefficient DMUs far away from the Pareto-efficient frontier improve to the ultimate Pareto-efficient frontier step by step. Taking the DMU $C$ in Figure 3 as an example, for example, $C^{1}, C^{2}$, and $\mathrm{C}^{3}$, are the three closest targets located on the first-level, 


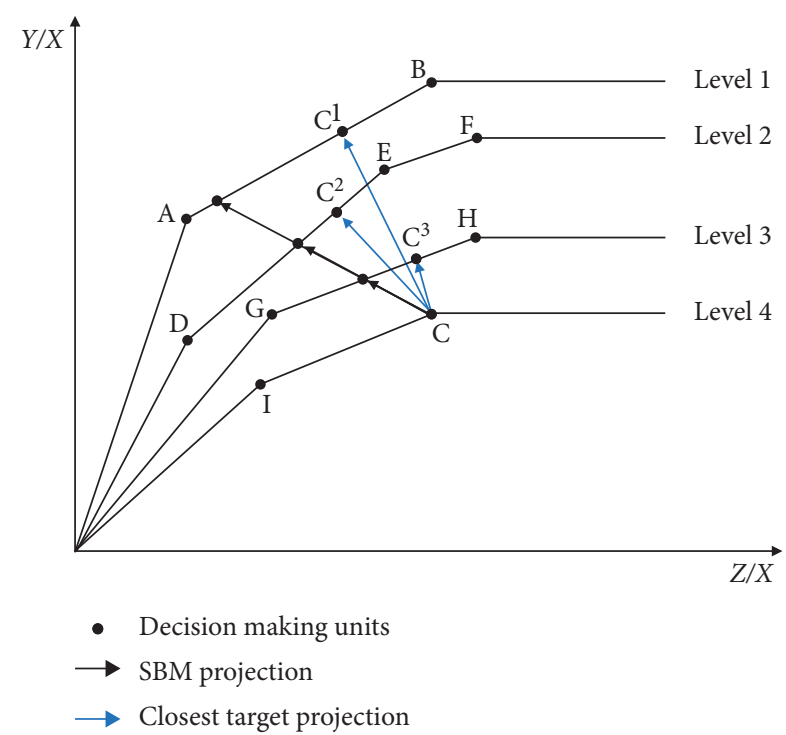

Figure 3: Stepwise projection based on closest target.

second-level, and third-level frontiers, respectively. We should note that $\mathrm{C}^{3}$ is the easiest target for $\mathrm{DMU}_{\mathrm{C}}$ to achieve, followed by $\mathrm{C}^{2}$ and $\mathrm{C}^{1}$.

\section{Empirical Study}

5.1. Background and Dataset. With the rapid economic growth and urbanization, China's transportation industry is developing rapidly. The passenger and freight turnover volumes in China have also grown with high-speed since 2000 , i.e., the passenger turnover volumes increased from 1.23 trillion passenger-kilometers in 2000 to 3.42 trillion passenger-kilometers in 2018, and the freight turnover increased from 4.43 trillion ton-kilometers to 20.47 trillion ton-kilometers [1]. The transportation industry is in a period of rapid growth, the massive use of energy, and the generation of large amounts of $\mathrm{CO}_{2}$ emissions which result in huge pressure on the environment. Therefore, it is necessary to evaluate and improve the environmental performance of China's transportation industry. Specifically, in this section, we mainly focus on the evaluation and improvement of environmental performance in transportation industry of 30 provincial-level regions (this study refers provincial-level regions to provinces for convenience) in China's mainland from 2010 to 2017 (Tibet is excluded due to the missing data).

Referring to Cui and Li et al. [29] and Wu et al. [18], we select the number of staff working in the transportation industry (Labor), transportation fixed assets investment (Capital), and energy consumption of the transportation industry (Energy consumption) as three inputs. Freight turnover volume (FTV) and passenger turnover volume (PTV) are two desirable outputs, and $\mathrm{CO}_{2}$ emissions are the undesirable output. The data related to inputs (Labor, Capital, and Energy consumption) and desirable outputs (FTV and PTV) were extracted from China Statistical Yearbook 2011-2018, China Energy Statistical Yearbook
2011-2018, and Ministry of Transport of the People's Republic.

Because the official data of provincial $\mathrm{CO}_{2}$ emissions in China are not directly provided, following Chang et al. [10] and $\mathrm{Wu}$ et al. [18], we use a fuel-based carbon footprint model to measure the $\mathrm{CO}_{2}$ emissions in the regional transportation industry. According to the Intergovernmental Panel on Climate Change guidelines [59], we calculate the $\mathrm{CO}_{2}$ emissions by the following equation:

$$
\mathrm{CO}_{2}=\sum_{i=1}^{n} E \times \mathrm{CCF}_{i} \times \mathrm{HE}_{i} \times \mathrm{COF}_{i} \times \frac{44}{12}
$$

where $\mathrm{CO}_{2}$ denotes the $\mathrm{CO}_{2}$ emissions (unit: ten thousand tons); $E$ represents the carbonaceous fuel; $\mathrm{CCF}_{i}$ denotes the carbon content factor of fuel $i \mathrm{HE}_{i}$ is the heat equivalent of fuel $i$; $\mathrm{COF}_{i}$ represents the carbon oxidation factor of fuel $i$; and 44/12 represents the ratio of the molecular weight of $\mathrm{CO}_{2}$ to the molecular weight of carbon. For the standard of carbon dioxide emission factor, we applied National Development and Reform Commission (NDRC) (2007) in China which has been successfully used by Chang et al. [10] and $\mathrm{Wu}$ et al. [18]. Also, the amount of consumption of each fuel by each province in the transportation industry is from China Energy Statistical Yearbook 2011-2018. A statistical description of the inputs and outputs is reported in Table 1.

5.2. Environmental Performance Analysis. By calculating model (2), we obtain the environmental performance of the transportation industry in 30 provincial regions of China from 2010 to 2017, and the results are reported in Table 2. To be specific, columns 1 and 2 present the three regions and the 30 provinces, respectively. Columns 3-10 provide the environmental performance from 2010 to 2017, and the last column presents the mean value of environmental performance across the whole observation period. We can draw the following conclusions from Table 2. First, the average annual environmental performance from 2010 to 2017 was 0.4763 , which reveals that there is a huge waste of energy in the transportation industry. Second, there are 10 provinces with an average annual environmental performance greater than 0.4763 over these eight years. The top five provinces with the highest average environmental performance in the transportation industry were Shanghai (1.0000), Anhui (0.9681), Henan (0.8705), Jiangxi (0.8088), and Hebei (0.7918), respectively. They all belong to the eastern and central regions. The last five provinces with poor environmental performance were Yunnan (0.1709), Sichuan (0.2269), Qinghai (0.2314), Inner Mongolia (0.2607), and Guizhou (0.2910), which all belong to the western region. Third, Shanghai performed the best environmental performance from 2010 to 2017 with a performance score of 1 in each year. Yunnan had the minimum average annual environmental performance which was 0.1709 , which indicates that there is a large gap in the environmental performance of the transportation industry in various provinces.

Also, the environmental performance of the transportation industry in 30 provincial-level regions obtained 
TABLE 1: Statistical description of the inputs and outputs.

\begin{tabular}{|c|c|c|c|c|c|c|}
\hline & Variables & Unit & Mean & S.D. & $\min$. & $\max$. \\
\hline \multirow{3}{*}{ Input } & Labor & $10^{3}$ persons & 221.19 & 135.72 & 26.31 & 706.34 \\
\hline & Capital & $10^{\frac{1}{8}}$ yuan & 558.17 & 353.01 & 55.04 & 1872.55 \\
\hline & Energy consumption & $10^{4}$ tce & 1031.99 & 622.13 & 108.84 & 3278.28 \\
\hline \multirow{2}{*}{ Desirable output } & Freight turnover volume & $10^{8}$ ton-km & 804.11 & 547.95 & 94.88 & 2998.23 \\
\hline & Passenger turnover volume & $10^{8}$ passenger-km & 5256.61 & 4857.81 & 419.68 & 27919.79 \\
\hline Undesirable output & $\mathrm{CO}_{2}$ & $10^{4}$ ton & 2197.95 & 1324.00 & 234.28 & 6924.63 \\
\hline
\end{tabular}

TABLE 2: Environmental performance of 30 Chinese provincial transportation industries (SBM model).

\begin{tabular}{|c|c|c|c|c|c|c|c|c|c|c|}
\hline Area & Province & 2010 & 2011 & 2012 & 2013 & 2014 & 2015 & 2016 & 2017 & Mean \\
\hline \multirow{11}{*}{ Eastern } & Beijing & 0.1773 & 0.1966 & 0.2005 & 0.2105 & 0.2312 & 1.0000 & 0.1900 & 0.1320 & 0.2922 \\
\hline & Tianjin & 1.0000 & 1.0000 & 1.0000 & 0.4567 & 0.4310 & 0.4693 & 0.6086 & 1.0000 & 0.7457 \\
\hline & Hebei & 0.4448 & 0.4966 & 0.6208 & 0.7719 & 1.0000 & 1.0000 & 1.0000 & 1.0000 & 0.7918 \\
\hline & Liaoning & 0.3708 & 0.3889 & 0.5164 & 1.0000 & 1.0000 & 1.0000 & 1.0000 & 1.0000 & 0.7845 \\
\hline & Shandong & 0.4248 & 0.4421 & 0.3931 & 0.4884 & 0.4621 & 0.5452 & 0.5071 & 0.4148 & 0.4597 \\
\hline & Shanghai & 1.0000 & 1.0000 & 1.0000 & 1.0000 & 1.0000 & 1.0000 & 1.0000 & 1.0000 & 1.0000 \\
\hline & Jiangsu & 0.3107 & 0.3631 & 0.4441 & 0.6394 & 0.6136 & 0.6509 & 0.6532 & 0.5670 & 0.5303 \\
\hline & Zhejiang & 0.3472 & 0.3752 & 0.4137 & 0.4858 & 0.4671 & 0.5858 & 0.5631 & 0.4420 & 0.4600 \\
\hline & Fujian & 0.1904 & 0.1995 & 0.2248 & 0.2977 & 0.3244 & 0.3967 & 0.4266 & 0.3624 & 0.3028 \\
\hline & Guangdong & 0.2360 & 0.2948 & 0.4202 & 0.4223 & 0.5587 & 0.5189 & 0.6432 & 0.6135 & 0.4634 \\
\hline & Hainan & 0.2874 & 0.3352 & 0.3464 & 0.2599 & 0.4436 & 0.4117 & 0.3084 & 0.2481 & 0.3301 \\
\hline \multirow{8}{*}{ Central } & Shanxi & 0.1535 & 0.1608 & 0.1879 & 0.3023 & 0.3575 & 0.4181 & 0.4496 & 0.3499 & 0.2974 \\
\hline & Jilin & 0.2016 & 0.2990 & 0.3854 & 0.5669 & 0.3512 & 0.3661 & 0.3606 & 0.3603 & 0.3614 \\
\hline & Heilongjiang & 0.1870 & 0.1694 & 0.2250 & 0.4776 & 0.4079 & 0.4343 & 0.3725 & 0.3189 & 0.3241 \\
\hline & Anhui & 1.0000 & 1.0000 & 1.0000 & 1.0000 & 1.0000 & 1.0000 & 1.0000 & 0.7448 & 0.9681 \\
\hline & Jiangxi & 0.4378 & 0.4691 & 0.5638 & 1.0000 & 1.0000 & 1.0000 & 1.0000 & 1.0000 & 0.8088 \\
\hline & Henan & 0.6543 & 0.6472 & 0.6628 & 1.0000 & 1.0000 & 1.0000 & 1.0000 & 1.0000 & 0.8705 \\
\hline & Hubei & 0.2178 & 0.2524 & 0.3109 & 0.3708 & 0.3717 & 0.4817 & 0.4792 & 0.4126 & 0.3621 \\
\hline & Hunan & 0.3056 & 0.3245 & 0.4024 & 1.0000 & 1.0000 & 1.0000 & 1.0000 & 1.0000 & 0.7541 \\
\hline \multirow{12}{*}{ Western } & Inner Mongolia & 0.2289 & 0.2343 & 0.2366 & 0.2506 & 0.2391 & 0.2883 & 0.3046 & 0.3033 & 0.2607 \\
\hline & Guangxi & 0.2718 & 0.2986 & 0.3451 & 0.4067 & 0.3715 & 0.5178 & 0.5415 & 0.4488 & 0.4003 \\
\hline & Chongqing & 0.2055 & 0.2411 & 0.2678 & 0.2738 & 0.3143 & 0.3956 & 0.3664 & 0.2927 & 0.2946 \\
\hline & Sichuan & 0.1751 & 0.1891 & 0.2249 & 0.2827 & 0.2229 & 0.2792 & 0.2469 & 0.1945 & 0.2269 \\
\hline & Guizhou & 0.2079 & 0.2161 & 0.2338 & 0.2814 & 0.2717 & 0.3272 & 0.3578 & 0.4319 & 0.2910 \\
\hline & Yunnan & 0.1153 & 0.1331 & 0.1585 & 0.1941 & 0.1732 & 0.2127 & 0.2064 & 0.1738 & 0.1709 \\
\hline & Shaanxi & 0.2096 & 0.2434 & 0.3277 & 0.6054 & 0.4163 & 0.4810 & 0.5274 & 0.4144 & 0.4032 \\
\hline & Gansu & 0.3765 & 0.4309 & 0.4709 & 0.5035 & 0.4550 & 0.5808 & 0.5928 & 0.4536 & 0.4830 \\
\hline & Qinghai & 0.1816 & 0.1948 & 0.2152 & 0.2402 & 0.2429 & 0.2756 & 0.2746 & 0.2260 & 0.2314 \\
\hline & Ningxia & 0.3135 & 0.3224 & 0.3137 & 0.3841 & 0.3340 & 0.3866 & 0.3694 & 0.2684 & 0.3365 \\
\hline & Xinjiang & 0.2235 & 0.2167 & 0.2104 & 0.3153 & 0.3036 & 0.4536 & 0.3549 & 0.1818 & 0.2825 \\
\hline & Mean & 0.3485 & 0.3712 & 0.4108 & 0.5163 & 0.5121 & 0.5826 & 0.5568 & 0.5118 & 0.4763 \\
\hline
\end{tabular}

from the closest targets model (4) is listed in Table 3. First, the average annual environmental performance of China's transportation industry was 0.6733 over the eight years. Two-third of provinces' environmental performance exceeds the average annual environmental performance. Second, the eastern area performed the best $(0.7444)$, followed by the central area (0.7268) and the western area (0.5633). In the eastern area, the environmental performance of Shanghai's transportation industry was 1 while Beijing had the minimum (0.3723). In the central area, Anhui performed the best which was 0.9858 and the minimum was 0.4671 for Heilongjiang. In the western area, the maximum environmental performance was 0.7018 for Gansu and the minimum was 0.3718 for Yunnan.
Combining Tables 2 and 3 and Figure 4, we compare the environmental performance of the transportation industry of 30 provinces that, respectively, are obtained from the SBM model (2) and the closest targets model (4) and draw the following findings. First, the environmental performance calculated by the closest targets approach (4) was higher than that calculated by the SBM method (2) for each province. Second, there are 14 provinces that have environmental performance which exceeds the average in terms of the closest targets model (4), while 10 provinces in terms of the SBM model (2). Third, the central area performed the best in environmental performance under the SBM model (2) while the eastern area performed the best under the closest targets model (4), and the western area had the worst environmental 
TABLE 3: Environmental performance of 30 Chinese provincial transportation industries (closest targets model (4)).

\begin{tabular}{|c|c|c|c|c|c|c|c|c|c|c|}
\hline Area & Province & 2010 & 2011 & 2012 & 2013 & 2014 & 2015 & 2016 & 2017 & Mean \\
\hline \multirow{11}{*}{ Eastern } & Beijing & 0.2191 & 0.2215 & 0.2228 & 0.3441 & 0.3311 & 1.0000 & 0.3388 & 0.3010 & 0.3723 \\
\hline & Tianjin & 1.0000 & 1.0000 & 1.0000 & 0.7182 & 0.7510 & 0.8816 & 0.8167 & 1.0000 & 0.8959 \\
\hline & Hebei & 0.6652 & 0.7079 & 0.7440 & 0.8393 & 1.0000 & 1.0000 & 1.0000 & 1.0000 & 0.8696 \\
\hline & Liaoning & 0.7586 & 0.7066 & 0.7673 & 1.0000 & 1.0000 & 1.0000 & 1.0000 & 1.0000 & 0.9041 \\
\hline & Shandong & 0.6540 & 0.6236 & 0.5892 & 0.7728 & 0.7575 & 0.8459 & 0.7913 & 0.8355 & 0.7337 \\
\hline & Shanghai & 1.0000 & 1.0000 & 1.0000 & 1.0000 & 1.0000 & 1.0000 & 1.0000 & 1.0000 & 1.0000 \\
\hline & Jiangsu & 0.5440 & 0.5566 & 0.6308 & 0.9156 & 0.8880 & 0.8508 & 0.8353 & 0.9276 & 0.7686 \\
\hline & Zhejiang & 0.6258 & 0.6216 & 0.6647 & 0.7941 & 0.7893 & 0.8241 & 0.7919 & 0.7276 & 0.7299 \\
\hline & Fujian & 0.4741 & 0.4677 & 0.4824 & 0.6128 & 0.6746 & 0.7367 & 0.7090 & 0.7216 & 0.6099 \\
\hline & Guangdong & 0.4026 & 0.4427 & 0.5567 & 0.7121 & 0.8313 & 0.8502 & 0.8607 & 0.8739 & 0.6913 \\
\hline & Hainan & 0.5689 & 0.5675 & 0.5516 & 0.5264 & 0.7707 & 0.7211 & 0.5958 & 0.6072 & 0.6137 \\
\hline \multirow{8}{*}{ Central } & Shanxi & 0.4231 & 0.4211 & 0.4398 & 0.6166 & 0.6684 & 0.7705 & 0.6792 & 0.7175 & 0.5920 \\
\hline & Jilin & 0.3572 & 0.4549 & 0.4222 & 0.6450 & 0.6221 & 0.7412 & 0.6555 & 0.7476 & 0.5807 \\
\hline & Heilongjiang & 0.3643 & 0.3339 & 0.3666 & 0.4910 & 0.4686 & 0.7092 & 0.4631 & 0.5398 & 0.4671 \\
\hline & Anhui & 1.0000 & 1.0000 & 1.0000 & 1.0000 & 1.0000 & 1.0000 & 1.0000 & 0.8863 & 0.9858 \\
\hline & Jiangxi & 0.5540 & 0.5860 & 0.6362 & 1.0000 & 1.0000 & 1.0000 & 1.0000 & 1.0000 & 0.8470 \\
\hline & Henan & 0.7381 & 0.7441 & 0.7491 & 1.0000 & 1.0000 & 1.0000 & 1.0000 & 1.0000 & 0.9039 \\
\hline & Hubei & 0.3969 & 0.3878 & 0.4465 & 0.7407 & 0.7462 & 0.8290 & 0.8260 & 0.8538 & 0.6534 \\
\hline & Hunan & 0.4139 & 0.4240 & 0.4387 & 1.0000 & 1.0000 & 1.0000 & 1.0000 & 1.0000 & 0.7846 \\
\hline \multirow{12}{*}{ Western } & Inner Mongolia & 0.4982 & 0.4512 & 0.4386 & 0.5337 & 0.5352 & 0.5528 & 0.5997 & 0.6741 & 0.5354 \\
\hline & Guangxi & 0.4682 & 0.4805 & 0.5240 & 0.7209 & 0.7228 & 0.8402 & 0.8262 & 0.8022 & 0.6731 \\
\hline & Chongqing & 0.4434 & 0.4862 & 0.4776 & 0.5853 & 0.6387 & 0.8653 & 0.6643 & 0.6653 & 0.6033 \\
\hline & Sichuan & 0.2686 & 0.2601 & 0.2827 & 0.5623 & 0.5033 & 0.7118 & 0.5103 & 0.4960 & 0.4494 \\
\hline & Guizhou & 0.3172 & 0.2884 & 0.2912 & 0.6051 & 0.5914 & 0.6088 & 0.5997 & 0.6559 & 0.4947 \\
\hline & Yunnan & 0.2110 & 0.2083 & 0.2251 & 0.4751 & 0.4337 & 0.5227 & 0.4433 & 0.4555 & 0.3718 \\
\hline & Shaanxi & 0.4036 & 0.4172 & 0.4976 & 0.8530 & 0.7540 & 0.9650 & 0.8140 & 0.7516 & 0.6820 \\
\hline & Gansu & 0.5266 & 0.5483 & 0.5515 & 0.8314 & 0.7864 & 0.8899 & 0.7904 & 0.6900 & 0.7018 \\
\hline & Qinghai & 0.4051 & 0.4150 & 0.4079 & 0.5050 & 0.5266 & 0.6881 & 0.5220 & 0.5808 & 0.5063 \\
\hline & Ningxia & 0.6650 & 0.6131 & 0.5781 & 0.7392 & 0.6788 & 0.6674 & 0.6500 & 0.6114 & 0.6504 \\
\hline & Xinjiang & 0.4243 & 0.3763 & 0.3409 & 0.6555 & 0.6228 & 0.7673 & 0.5773 & 0.4649 & 0.5286 \\
\hline & Mean & 0.5264 & 0.5271 & 0.5441 & 0.7265 & 0.7364 & 0.8280 & 0.7453 & 0.7529 & 0.6733 \\
\hline
\end{tabular}

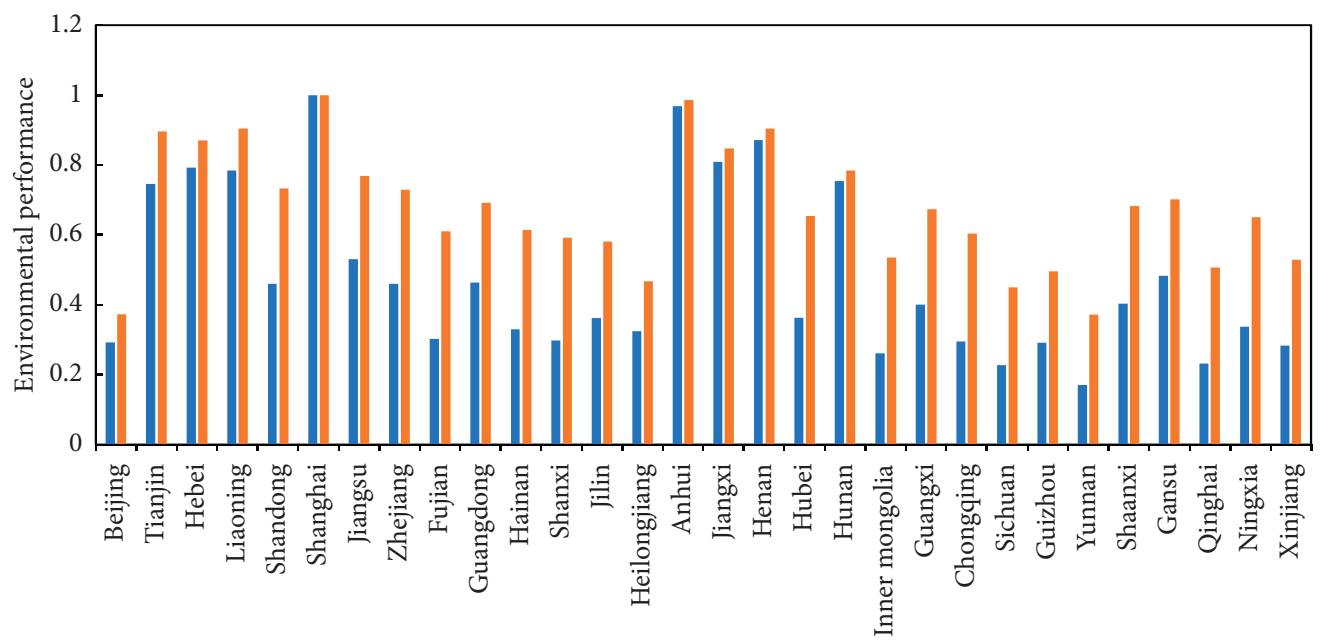

- SBM model

- Closest targets model

FIGURE 4: Comparison of the average environmental performance.

performance over the eight years in terms of both methods. Fourth, only Shanghai province performed the best in terms of the SBM model and closest targets approach while Yunnan province performed the worst.
5.3. Environmental Performance Improvement Projection Based on the SBM and Closest Targets Models. In this section, we chose the year 2017 as an example to demonstrate the environmental performance improvement projection based 
TABLE 4: Environmental performance improvement projection results.

\begin{tabular}{|c|c|c|c|c|c|c|c|}
\hline \multirow{2}{*}{ Province } & \multicolumn{3}{|c|}{ Input } & \multicolumn{2}{|c|}{ Desirable output } & \multirow{2}{*}{$\begin{array}{l}\text { Undesirable output } \\
\qquad \mathrm{CO}_{2}\end{array}$} & \multirow{2}{*}{ Score } \\
\hline & Labor & Capital & Energy & PTV & FTV & & \\
\hline \multirow{3}{*}{ Beijing } & 517.79 & 254.49 & 1263.53 & 253.16 & 958.42 & 2619.59 & \\
\hline & $55.95(89 \%)$ & $73.43(71 \%)$ & $180.87(86 \%)$ & $253.16(0 \%)$ & $1182.45(16 \%)$ & $377.18(86 \%)$ & 0.1320 \\
\hline & $240.74(54 \%)$ & $254.49(0 \%)$ & $773.91(39 \%)$ & $388.63(26 \%)$ & $1205.02(17 \%)$ & $1619.04(38 \%)$ & 0.3010 \\
\hline \multirow{3}{*}{ Shanxi } & 206.55 & 290.45 & 1010.52 & 373.76 & 4185.03 & 2143.22 & \\
\hline & $64.71(69 \%)$ & $212.27(27 \%)$ & $285.91(72 \%)$ & $401.18(6 \%)$ & $4185.03(0 \%)$ & $600.70(72 \%)$ & 0.3499 \\
\hline & $206.55(0 \%)$ & $290.45(0 \%)$ & $956.42(5 \%)$ & $649.91(30 \%)$ & $4185.03(0 \%)$ & $2024.94(6 \%)$ & 0.7175 \\
\hline \multirow{3}{*}{ Inner Mongolia } & 184.38 & 700.86 & 879.71 & 362.66 & 5146.76 & 1887.13 & \\
\hline & $79.59(57 \%)$ & $261.05(63 \%)$ & $351.61(60 \%)$ & $493.38(21 \%)$ & $5146.76(0 \%)$ & $738.75(61 \%)$ & 0.3033 \\
\hline & $184.38(0 \%)$ & $150.71(78 \%)$ & $879.71(0 \%)$ & $362.66(0 \%)$ & $6096.44(13 \%)$ & $1871.37(1 \%)$ & 0.6741 \\
\hline \multirow{3}{*}{ Jilin } & 124.04 & 244.47 & 694.29 & 425.36 & 1634.65 & 1544.33 & \\
\hline & $68.61(45 \%)$ & $225.06(8 \%)$ & $303.14(56 \%)$ & $425.36(0 \%)$ & $4437.25(39 \%)$ & $636.90(59 \%)$ & 0.3603 \\
\hline & $124.04(0 \%)$ & $244.47(0 \%)$ & $654.39(6 \%)$ & $525.02(16 \%)$ & $2246.98(21 \%)$ & $1403.78(9 \%)$ & 0.7476 \\
\hline \multirow{3}{*}{ Heilongjiang } & 220.33 & 208.91 & 1196.45 & 452.05 & 1657.69 & 2426.61 & \\
\hline & $80.48(63 \%)$ & $208.91(0 \%)$ & $322.38(73 \%)$ & $452.05(0 \%)$ & $3986.18(37 \%)$ & $675.92(72 \%)$ & 0.3189 \\
\hline & $220.33(0 \%)$ & $208.91(0 \%)$ & $1027.54(14 \%)$ & $568.31(17 \%)$ & $3083.05(32 \%)$ & $2129.68(12 \%)$ & 0.5398 \\
\hline \multirow{3}{*}{ Jiangsu } & 405.01 & 672.81 & 2086.08 & 1515.26 & 9057.60 & 4356.11 & \\
\hline & $276.62(32 \%)$ & $672.81(0 \%)$ & $1080.83(48 \%)$ & $1515.26(0 \%)$ & $12699.81(22 \%)$ & $2264.83(48 \%)$ & 0.5670 \\
\hline & $405.01(0 \%)$ & $672.81(0 \%)$ & $1915.84(8 \%)$ & $1614.78(6 \%)$ & $9057.60(0 \%)$ & $4051.45(7 \%)$ & 0.9276 \\
\hline \multirow{3}{*}{ Zhejiang } & 257.92 & 1556.07 & 1462.13 & 1096.04 & 10106.23 & 3103.11 & \\
\hline & $176.80(31 \%)$ & $579.92(63 \%)$ & $781.11(47 \%)$ & $1096.04(0 \%)$ & $11433.55(10 \%)$ & $1641.13(47 \%)$ & 0.4420 \\
\hline & $257.92(0 \%)$ & $951.73(39 \%)$ & $1462.13(0 \%)$ & $1563.26(23 \%)$ & $10106.23(0 \%)$ & $3095.47(0 \%)$ & 0.7276 \\
\hline \multirow{3}{*}{ Anhui } & 203.26 & 836.32 & 1043.40 & 1153.69 & 11429.77 & 2198.14 & \\
\hline & $186.10(8 \%)$ & $610.42(27 \%)$ & $822.19(21 \%)$ & $1153.69(0 \%)$ & $12034.88(5 \%)$ & $1727.44(21 \%)$ & 0.7448 \\
\hline & $203.26(0 \%)$ & $705.65(16 \%)$ & $1016.46(3 \%)$ & $1307.89(11 \%)$ & $11429.77(0 \%)$ & $2142.67(3 \%)$ & 0.8863 \\
\hline \multirow{3}{*}{ Fujian } & 202.06 & 890.26 & 1102.15 & 604.23 & 6779.76 & 2325.35 & \\
\hline & $104.84(48 \%)$ & $343.88(61 \%)$ & $463.17(58 \%)$ & $649.92(7 \%)$ & $6779.76(0 \%)$ & $973.14(58 \%)$ & 0.3624 \\
\hline & $202.06(0 \%)$ & $160.92(82 \%)$ & $1092.60(1 \%)$ & $604.23(0 \%)$ & $6829.83(1 \%)$ & $2325.35(0 \%)$ & 0.7216 \\
\hline \multirow{3}{*}{ Shandong } & 412.43 & 907.36 & 2144.70 & 1247.26 & 9719.46 & 4552.25 & \\
\hline & $201.19(51 \%)$ & $659.93(27 \%)$ & $888.87(59 \%)$ & $1247.26(0 \%)$ & $13011.02(20 \%)$ & $1867.55(59 \%)$ & 0.4148 \\
\hline & $412.43(0 \%)$ & $896.28(1 \%)$ & $2144.70(0 \%)$ & $1845.34(24 \%)$ & $9719.46(0 \%)$ & $4544.32(0 \%)$ & 0.8355 \\
\hline \multirow{3}{*}{ Hubei } & 292.94 & 987.15 & 1795.95 & 1278.14 & 6344.76 & 3785.23 & \\
\hline & $206.18(30 \%)$ & $676.27(31 \%)$ & $910.88(49 \%)$ & $1278.14(0 \%)$ & $13333.18(34 \%)$ & $1913.79(49 \%)$ & 0.4126 \\
\hline & $292.94(0 \%)$ & $865.18(12 \%)$ & $1785.06(1 \%)$ & $1673.09(19 \%)$ & $6344.76(0 \%)$ & $3785.23(0 \%)$ & 0.8538 \\
\hline \multirow{3}{*}{ Guangdong } & 706.34 & 1325.28 & 3278.28 & 2012.47 & 27919.79 & 6924.63 & \\
\hline & $438.19(38 \%)$ & $1325.28(0 \%)$ & $1977.19(40 \%)$ & $2466.13(16 \%)$ & $27919.79(0 \%)$ & $4162.16(40 \%)$ & 0.6135 \\
\hline & $706.34(0 \%)$ & $829.08(37 \%)$ & $3265.91(0 \%)$ & $2012.47(0 \%)$ & $27919.79(0 \%)$ & $6924.63(0 \%)$ & 0.8739 \\
\hline & 157.67 & 802.96 & 969.08 & 778.31 & 4613.32 & 2051.94 & \\
\hline Guangxi & $125.55(20 \%)$ & $411.81(49 \%)$ & $554.67(43 \%)$ & $778.31(0 \%)$ & $8119.14(30 \%)$ & $1165.39(43 \%)$ & 0.4488 \\
\hline & $157.67(0 \%)$ & $544.27(32 \%)$ & $967.83(0 \%)$ & $988.48(18 \%)$ & $4613.32(0 \%)$ & $2051.94(0 \%)$ & 0.8022 \\
\hline & 61.10 & 172.35 & 293.12 & 129.29 & 864.26 & 608.46 & \\
\hline Hainan & $20.86(66 \%)$ & $68.41(60 \%)$ & $92.14(69 \%)$ & $129.29(0 \%)$ & $1348.72(26 \%)$ & $193.59(68 \%)$ & 0.2481 \\
\hline & $61.10(0 \%)$ & $114.43(34 \%)$ & $288.99(1 \%)$ & $203.37(27 \%)$ & $1084.97(17 \%)$ & $608.46(0 \%)$ & 0.6072 \\
\hline & 238.76 & 504.49 & 972.33 & 496.34 & 3374.34 & 2023.75 & \\
\hline Chongqing & $80.06(66 \%)$ & $262.62(48 \%)$ & $353.72(64 \%)$ & $496.34(0 \%)$ & $5177.68(26 \%)$ & $743.18(63 \%)$ & 0.2927 \\
\hline & $181.99(24 \%)$ & $432.67(14 \%)$ & $957.83(1 \%)$ & $798.64(27 \%)$ & $3374.34(0 \%)$ & $2023.75(0 \%)$ & 0.6653 \\
\hline & 315.40 & 1457.44 & 1583.01 & 881.52 & 2696.17 & 3248.94 & \\
\hline Sichuan & $142.20(55 \%)$ & $466.41(68 \%)$ & $628.22(60 \%)$ & $881.52(0 \%)$ & $9195.69(41 \%)$ & $1319.91(59 \%)$ & 0.1945 \\
\hline & $315.40(0 \%)$ & $862.27(41 \%)$ & $1551.79(2 \%)$ & $1128.88(18 \%)$ & $4861.78(31 \%)$ & $3248.94(0 \%)$ & 0.4960 \\
\hline & 104.80 & 1650.62 & 687.26 & 720.13 & 1656.48 & 1439.64 & \\
\hline Guizhou & $104.80(0 \%)$ & $383.22(77 \%)$ & $608.94(11 \%)$ & $720.13(0 \%)$ & $4637.58(39 \%)$ & $1288.29(11 \%)$ & 0.4319 \\
\hline & $104.80(0 \%)$ & $501.21(70 \%)$ & $679.56(1 \%)$ & $720.13(0 \%)$ & $2194.34(20 \%)$ & $1439.64(0 \%)$ & 0.6559 \\
\hline & 158.75 & 1600.46 & 1047.92 & 453.39 & 1824.96 & 2223.38 & \\
\hline Yunnan & $73.14(54 \%)$ & $239.89(\mathrm{a} 85 \%)$ & $323.11(69 \%)$ & $453.39(0 \%)$ & $4729.58(38 \%)$ & $678.87(69 \%)$ & 0.1738 \\
\hline & $158.75(0 \%)$ & $973.74(39 \%)$ & $1047.37(0 \%)$ & $795.26(30 \%)$ & $2714.52(25 \%)$ & $2223.38(0 \%)$ & 0.4555 \\
\hline
\end{tabular}


TABle 4: Continued.

\begin{tabular}{|c|c|c|c|c|c|c|c|}
\hline \multirow{2}{*}{ Province } & \multicolumn{3}{|c|}{ Input } & \multicolumn{2}{|c|}{ Desirable output } & \multirow{2}{*}{$\begin{array}{l}\text { Undesirable output } \\
\qquad \mathrm{CO}_{2}\end{array}$} & \multirow{2}{*}{ Score } \\
\hline & Labor & Capital & Energy & PTV & FTV & & \\
\hline \multirow{3}{*}{ Shaanxi } & 235.19 & 590.17 & 845.14 & 760.86 & 3760.64 & 1733.97 & \\
\hline & $122.73(48 \%)$ & $402.57(32 \%)$ & $542.24(36 \%)$ & $760.86(0 \%)$ & $7937.07(34 \%)$ & $1139.26(34 \%)$ & 0.4144 \\
\hline & $191.17(19 \%)$ & $277.27(53 \%)$ & $821.58(3 \%)$ & $760.86(0 \%)$ & $3760.64(0 \%)$ & $1733.97(0 \%)$ & 0.7516 \\
\hline \multirow{3}{*}{ Gansu } & 113.54 & 865.34 & 489.76 & 619.65 & 2439.66 & 1048.07 & \\
\hline & $99.96(12 \%)$ & $327.86(62 \%)$ & $441.60(10 \%)$ & $619.65(0 \%)$ & $6463.98(38 \%)$ & $927.81(11 \%)$ & 0.4536 \\
\hline & $113.54(0 \%)$ & $311.16(64 \%)$ & $489.76(0 \%)$ & $619.65(0 \%)$ & $3107.86(18 \%)$ & $1031.57(2 \%)$ & 0.6900 \\
\hline \multirow{3}{*}{ Qinghai } & 42.75 & 446.61 & 193.46 & 136.80 & 519.46 & 397.67 & \\
\hline & $22.07(48 \%)$ & $72.38(84 \%)$ & $97.49(50 \%)$ & $136.80(0 \%)$ & $1427.08(39 \%)$ & $204.84(48 \%)$ & 0.2260 \\
\hline & $42.75(0 \%)$ & $117.22(74 \%)$ & $188.89(2 \%)$ & $142.05(4 \%)$ & $757.49(24 \%)$ & $397.67(0 \%)$ & 0.5808 \\
\hline \multirow{3}{*}{ Ningxia } & 32.64 & 200.45 & 213.50 & 99.19 & 753.72 & 439.76 & \\
\hline & $16.00(51 \%)$ & $52.48(74 \%)$ & $70.69(67 \%)$ & $99.19(0 \%)$ & $1034.72(21 \%)$ & $148.52(66 \%)$ & 0.2684 \\
\hline & $32.64(0 \%)$ & $130.03(35 \%)$ & $208.86(2 \%)$ & $177.81(31 \%)$ & $753.72(0 \%)$ & $439.76(0 \%)$ & 0.6114 \\
\hline \multirow{3}{*}{ Xinjiang } & 153.21 & 1872.55 & 1042.84 & 428.54 & 2176.35 & 2170.89 & \\
\hline & $69.13(55 \%)$ & $226.74(88 \%)$ & $305.40(71 \%)$ & $428.54(0 \%)$ & $4470.40(34 \%)$ & $641.66(70 \%)$ & 0.1818 \\
\hline & $153.21(0 \%)$ & $1040.52(44 \%)$ & $1030.09(1 \%)$ & $791.92(31 \%)$ & $2831.29(19 \%)$ & $2170.89(0 \%)$ & 0.4649 \\
\hline
\end{tabular}

TABle 5: Environmental performance improvement projection results for the nearest upper-level efficient frontier.

\begin{tabular}{|c|c|c|c|c|c|c|c|c|}
\hline & \multirow{2}{*}{ Province } & \multicolumn{3}{|c|}{ Input } & \multicolumn{2}{|c|}{ Desirable output } & \multirow{2}{*}{$\begin{array}{l}\text { Undesirable output } \\
\qquad \mathrm{CO}_{2}\end{array}$} & \multirow{2}{*}{ Score } \\
\hline & & Labor & Capital & Energy & PTV & FTV & & \\
\hline \multirow{15}{*}{ E2 } & \multirow{3}{*}{ Jiangsu } & 405.01 & 672.81 & 2086.08 & 1515.26 & 9057.60 & 4356.11 & \\
\hline & & $276.62(32 \%)$ & $672.81(0 \%)$ & $1080.83(48 \%)$ & $1515.26(0 \%)$ & $12699.81(40 \%)$ & $2264.83(48 \%)$ & 0.5670 \\
\hline & & $405.01(0 \%)$ & $672.81(0 \%)$ & $1915.84(8 \%)$ & $1614.78(7 \%)$ & $9057.60(0 \%)$ & $4051.45(7 \%)$ & 0.9276 \\
\hline & \multirow{3}{*}{ Anhui } & 203.26 & 836.32 & 1043.40 & 1153.69 & 11429.77 & 2198.14 & \\
\hline & & $186.10(8 \%)$ & $610.42(27 \%)$ & $822.19(21 \%)$ & $1153.69(0 \%)$ & $12034.88(5 \%)$ & $1727.44(21 \%)$ & 0.7448 \\
\hline & & $203.26(0 \%)$ & $705.65(16 \%)$ & $1016.46(3 \%)$ & $1307.89(13 \%)$ & $11429.77(0 \%)$ & $2142.67(3 \%)$ & 0.8863 \\
\hline & \multirow{3}{*}{ Guangdong } & 706.34 & 1325.28 & 3278.28 & 2012.47 & 27919.79 & 6924.63 & \\
\hline & & $438.19(38 \%)$ & $1325.28(0 \%)$ & $1977.19(40 \%)$ & $2466.13(23 \%)$ & $27919.79(0 \%)$ & $4162.16(40 \%)$ & 0.6135 \\
\hline & & $706.34(0 \%)$ & $829.08(37 \%)$ & $3265.91(0 \%)$ & $2012.47(0 \%)$ & $27919.79(0 \%)$ & $6924.63(0 \%)$ & 0.8739 \\
\hline & \multirow{4}{*}{ Guizhou } & 104.80 & 1650.62 & 687.26 & 720.13 & 1656.48 & 1439.64 & \\
\hline & & $104.80(0 \%)$ & $383.22(77 \%)$ & $608.94(11 \%)$ & $720.13(0 \%)$ & $4637.58(180 \%)$ & $1288.29(11 \%)$ & 0.4319 \\
\hline & & $104.80(0 \%)$ & $501.21(70 \%)$ & $679.56(1 \%)$ & $720.13(0 \%)$ & $2194.34(32 \%)$ & $1439.64(0 \%)$ & 0.6559 \\
\hline & & 113.54 & 865.34 & 489.76 & 619.65 & 2439.66 & 1048.07 & \\
\hline & \multirow[t]{2}{*}{ Gansu } & $99.96(12 \%)$ & $327.86(62 \%)$ & $441.60(10 \%)$ & $619.65(0 \%)$ & $6463.98(165 \%)$ & $927.81(11 \%)$ & 0.4536 \\
\hline & & $113.54(0 \%)$ & $311.16(64 \%)$ & $489.76(0 \%)$ & $619.65(0 \%)$ & $3107.86(27 \%)$ & $1031.57(2 \%)$ & 0.6900 \\
\hline
\end{tabular}


TABle 5: Continued.

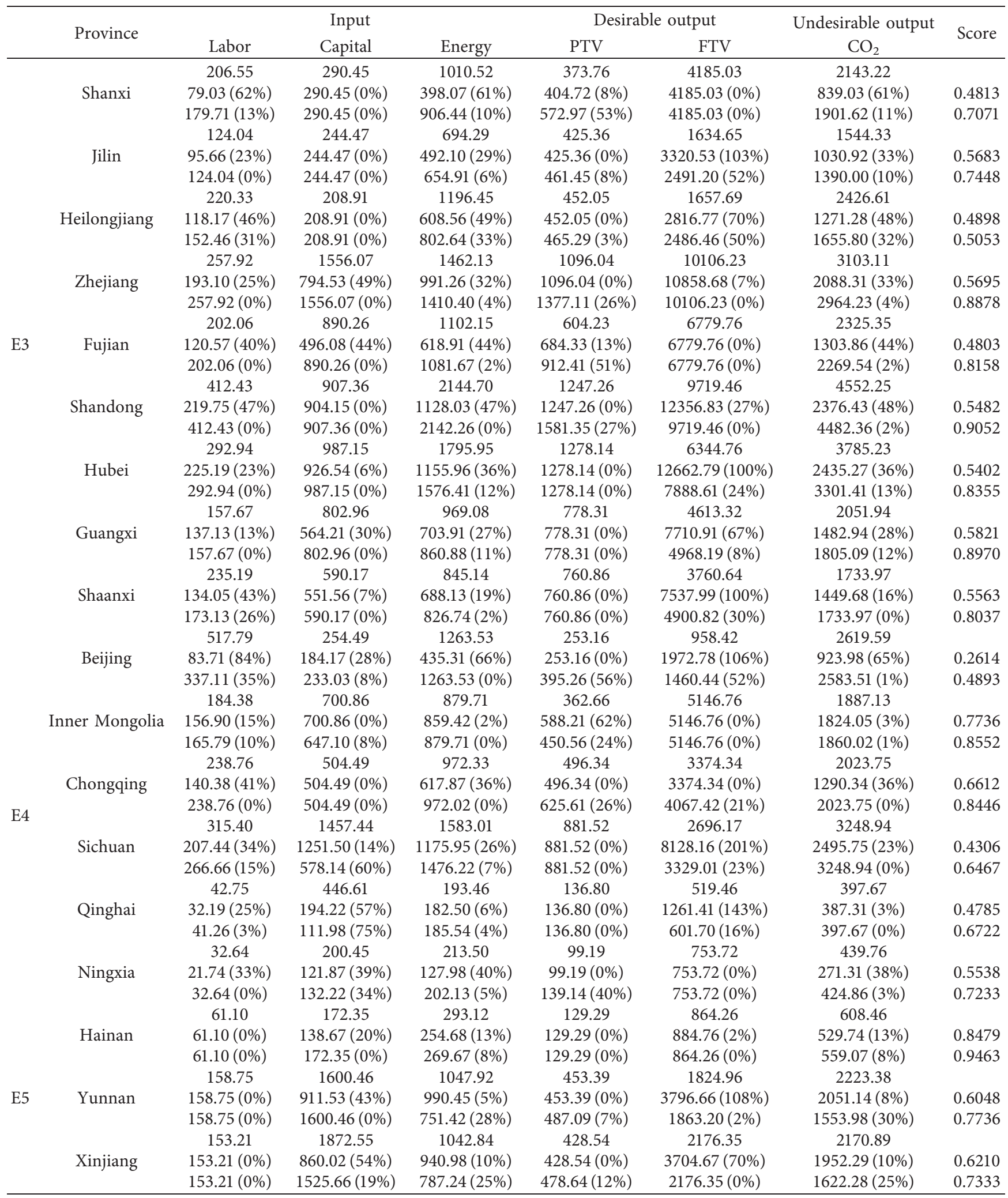


TABLE 6: Stepwise environmental performance improvement projection results for all level efficient frontiers of Hainan province.

\begin{tabular}{|c|c|c|c|c|c|c|c|}
\hline \multirow{2}{*}{ Province } & \multicolumn{3}{|c|}{ Input } & \multicolumn{2}{|c|}{ Desirable output } & \multirow{2}{*}{$\begin{array}{l}\text { Undesirable output } \\
\qquad \mathrm{CO}_{2}\end{array}$} & \multirow{2}{*}{ Score } \\
\hline & Labor & Capital & Energy & PTV & FTV & & \\
\hline Yunnan & 61.10 & 172.35 & 293.12 & 129.29 & 864.26 & 608.46 & \\
\hline E1 & $20.86(66 \%)$ & $68.41(60 \%)$ & $92.14(69 \%)$ & $129.29(0 \%)$ & $1348.72(56 \%)$ & $193.59(68 \%)$ & 0.2481 \\
\hline E1 & $61.10(0 \%)$ & $114.43(34 \%)$ & $288.99(1 \%)$ & $203.37(57 \%)$ & $1084.97(26 \%)$ & $608.46(0 \%)$ & 0.6072 \\
\hline E2 & $22.78(63 \%)$ & $93.72(46 \%)$ & $116.93(60 \%)$ & $129.29(0 \%)$ & $1280.91(48 \%)$ & $246.34(60 \%)$ & 0.3227 \\
\hline E2 & $56.63(7 \%)$ & $172.35(0 \%)$ & $291.76(0 \%)$ & $198.21(53 \%)$ & $1103.39(28 \%)$ & $608.46(0 \%)$ & 0.7042 \\
\hline E3 & $27.16(56 \%)$ & $144.92(16 \%)$ & $163.62(44 \%)$ & $129.29(0 \%)$ & $864.26(0 \%)$ & $346.65(43 \%)$ & 0.5375 \\
\hline E3 & $55.91(8 \%)$ & $81.12(53 \%)$ & $292.93(0 \%)$ & $129.29(0 \%)$ & $864.26(0 \%)$ & $608.46(0 \%)$ & 0.7950 \\
\hline $\mathrm{E} 4$ & $61.10(0 \%)$ & $138.67(20 \%)$ & $254.68(13 \%)$ & $129.29(0 \%)$ & $884.76(2 \%)$ & $529.74(13 \%)$ & 0.8479 \\
\hline $\mathrm{E} 4$ & $61.10(0 \%)$ & $172.35(0 \%)$ & $269.67(8 \%)$ & $129.29(0 \%)$ & $864.26(0 \%)$ & $559.07(8 \%)$ & 0.9463 \\
\hline
\end{tabular}

on the SBM model (2) and closest targets approach (4). From Tables 2 and 3, we find that 7 provinces are efficient in 2017 in terms of both methods. Here, we mainly pay attention to the improvement of inefficient provinces.

Table 4 provides the environmental performance improvement projections of the inefficient provinces in terms of the SBM model (2) and closest targets model (4). To be specific, the first row shows the original values of the inputs and outputs of each province. The improvement targets obtained from the SBM model (2) and closest targets method (4) are presented in the second row and third row, respectively. To be more intuitive, the proportions of the original value relative to the projected targets that need to be increased/decreased (improvement percentages) are presented in parentheses. Taking Jiangsu province as an example, its original values of inputs, desirable outputs, and undesirable output are 505.01, 672.81, $2086.08,1515.26,9057.60$, and 4356.11, respectively. Its inputs/ outputs targets are $276.62,672.81,1080.83,1515.26,12699.81$, and 2264.83 with respect to the SBM model (2), while the targets change to $405.01,672.81,1915.84,1614.78,9057.60$, and 4051.45 with respect to the closest targets model (4). These figures show that Jiangsu province can become efficient by reducing two inputs (labor by $32 \%$ and energy by $48 \%$ ) and the undesirable output $\left(\mathrm{CO}_{2}\right.$ by $\left.48 \%\right)$, while increasing one desirable output (FTV by $22 \%$ ) based on the SBM model (2). However, in terms of the closest targets model (4), Jiangsu province achieves efficiency by reducing energy by $8 \%$ and $\mathrm{CO}_{2}$ by $7 \%$, while increasing PTV by $6 \%$. It indicates that the closest targets may be more easily achieved with less improvement than a conventional radial model.

\subsection{Stepwise Environmental Performance Improvement} Projection Based on the SBM and Closest Targets Models. Utilizing the calculation steps proposed by Seiford and Zhu [58], 30 provinces are divided into five different levels of efficient frontiers, and columns 1 and 2 in Table 5 report these levels of the efficient frontier and the provinces they contain. In addition, Table 5 gives the stepwise improvement targets for the inefficient provinces based on the SBM model and closest targets model. To be specific, for each province that is inefficient at a particular level, its original values of inputs and outputs are presented in the first row, and the stepwise improvement targets calculated by the SBM and closest targets model are listed in the second row and third

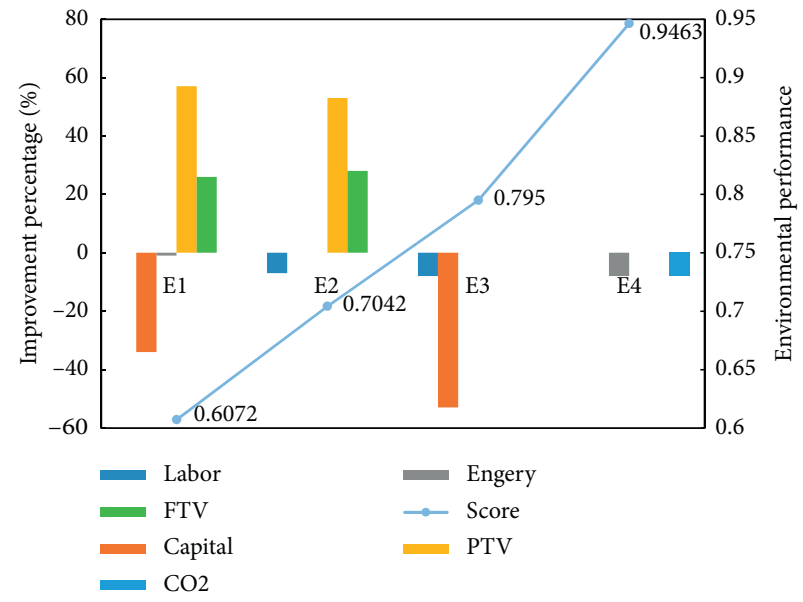

FIGURE 5: Environmental performance improvement projection results of Hainan based on the stepwise-closest targets model.

row, i.e., row "E2" lists the targets located on the level 1 efficient frontier, namely, the ultimate frontier, row "E3" gives the targets located on the level 2 efficient frontier, and so on.

We still take Jiangsu province as an example. It is identified as efficient in the level 2 frontier, which means it can improve to the level 1 frontier in one step. The targets yielded by the stepwise-closest targets model prove that this province would achieve efficiency by reducing one input (energy by $8 \%$ ) and one undesirable output $\left(\mathrm{CO}_{2}\right.$ by $\left.7 \%\right)$ while increasing one desirable output (PTV by 7\%). However, it becomes efficient by adjusting two inputs (reduce labor by $32 \%$ and energy by $48 \%$ ), one desirable output (increase FTV by $40 \%$ ), and one undesirable output (reduce $\mathrm{CO}_{2}$ by $48 \%$ ) with the SBM model. That is, Jiangsu province can achieve the closest targets more easily. Note that we assume that reducing the number of input/output variables to change makes a change easier without considering the improvement costs of inputs and/or outputs. This is a reasonable simplifying assumption although in real-life situations it may be harder to change one variable by $1 \%$ than another variable by $10 \%$.

Moreover, we choose Hainan province which is at the lowest efficiency level (E5) as another example. Table 6 reports the stepwise targets of Hainan based on the SBM model and closest targets model, and Figure 5 clearly demonstrates the corresponding improvement percentages 
for different levels in terms of the stepwise-closest targets model. Hainan is located on the level 5 frontier, which means that it needs four steps to achieve efficiency. For example, Hainan can improve to the level 4 efficient frontier by reducing energy by $8 \%$ and $\mathrm{CO}_{2}$ by $8 \%$ when using the closest targets model and achieve the environmental efficiency of 0.9463 .

In summary, compared with the SBM model, the closest targets model can generate easier and closer achieved targets for the inefficient provinces. An inefficient province would become efficient with the minimization of reduction of inputs and undesirable outputs and/or augmentation of desirable outputs.

\section{Conclusion}

The transportation industry has greatly promoted China's economic development but also is a major source of $\mathrm{CO}_{2}$ emissions, which hurt the environment. Therefore, it is necessary to measure and improve its environmental performance. In the current study, using the data of the transportation industry of 30 provincial-level regions in China during the period of 2010-2017, we incorporate the closest targets and context-dependent DEA model to evaluate the environmental performance. Moreover, our proposed stepwise-closest targets method can identify a sequence of intermediate closest targets and form a stepwise projection path for each inefficient province so as to achieve the goal of improving environmental performance with less effort. We draw the following findings from the empirical study.

First, the environmental performance of the transportation industry obtained from the closest targets model is greater than that obtained from the SBM model for each province. Among the three areas, the eastern area performed best in environmental performance, followed by the central area, and the western area performed the worst. Only Shanghai province performed the best in terms of the SBM model and closest targets approach while Yunnan province performed the worst.

Second, compared with the conventional SBM model, the closest targets model can generate easier and closer achieved targets for the inefficient provinces. An inefficient province may not achieve efficiency in a short time when a large efficiency gap exists between it and efficient frontier, and the stepwise-closest targets model can help the inefficient province to improve to efficiency using several intermediate closest targets, each of which can encourage the province to continue its improvement efforts.

There are three provinces (Hainan, Yunnan, and Xinjiang) with the lowest environmental performance, which need four steps to achieve efficiency.

This study is not free of limitations, and several future research directions should be considered. First, our study's method directs the inefficient DMUs to the Pareto-efficient frontier via a path consisting of several intermediate closest targets, and these targets are hypothetical DMUs, so we suggest limiting the intermediate targets to the existing
DMUs in the future study. Second, future methods could also take varying improvement costs of inputs and outputs into consideration and find a path with the minimum improvement costs.

\section{Data Availability}

The data generated or analyzed during this study are included in this published article (and its supplementary information file). The datasets generated during and/or analyzed during the current study are available in the National Bureau of Statistics of China (http://www.stats.gov.cn/ tjsj/ndsj/) and Ministry of Transport of the People's Republic of China (http://www.mot.gov.cn/shuju/).

\section{Conflicts of Interest}

The authors declare that they have no conflicts of interest.

\section{Acknowledgments}

This research was funded by the National Social Science Fund, China (no. 17BJY071).

\section{References}

[1] China Statistical Yearbook, 2019, http://www.stats.gov.cn/tjsj/ ndsj.

[2] X. Shi, "Environmental efficiency evaluation of Chinese industry systems by using non-cooperative two-stage DEA model," Mathematical Problems in Engineering, pp. 16-18, 2019.

[3] C. Bai, L. Zhou, M. Xia, and C. Feng, "Analysis of the spatial association network structure of China's transportation carbon emissions and its driving factors," Journal of Environmental Management, vol. 253, p. 109765, 2020.

[4] China Energy Development Report, 2018, https://www.cers. org.cn/energy.aspx?category_id=1240.

[5] Y. Li, Q. Du, X. Lu, J. Wu, and X. Han, "Relationship between the development and $\mathrm{CO} 2$ emissions of transport sector in China," Transportation Research Part D: Transport and Environment, vol. 74, pp. 1-14, 2019.

[6] S. Lu, H. Jiang, Y. Liu, and S. Huang, "Regional disparities and influencing factors of average $\mathrm{CO} 2$ emissions from transportation industry in Yangtze river economic Belt," Transportation Research Part D: Transport and Environment, vol. 57, pp. 112-123, 2017.

[7] W. Chen and Y. Lei, "Path analysis of factors in energy-related CO2 emissions from Beijing's transportation sector," Transportation Research Part D: Transport and Environment, vol. 50, pp. 473-487, 2017.

[8] C. Bai, Y. Mao, Y. Gong, and C. Feng, "Club convergence and factors of per capita transportation carbon emissions in China," Sustainability, vol. 11, no. 2, p. 539, 2019.

[9] H. Wang, X. Ou, and X. Zhang, "Mode, technology, energy consumption, and resulting $\mathrm{CO} 2$ emissions in China's transport sector up to 2050," Energy Policy, vol. 109, pp. 719-733, 2017.

[10] Y.-T. Chang, N. Zhang, D. Danao, and N. Zhang, "Environmental efficiency analysis of transportation system in China: a non-radial DEA approach,” Energy Policy, vol. 58, pp. 277-283, 2013. 
[11] Y. S. Park, S. H. Lim, G. Egilmez, and J. Szmerekovsky, "Environmental efficiency assessment of U.S. transport sector: a slack-based data envelopment analysis approach," Transportation Research Part D: Transport and Environment, vol. 61, pp. 152-164, 2018.

[12] A. Charnes, W. W. Cooper, and E. Rhodes, "Measuring the efficiency of decision making units," European Journal of Operational Research, vol. 2, no. 6, pp. 429-444, 1978.

[13] W. D. Cook and L. M. Seiford, "Data envelopment analysis (DEA) - thirty years on," European Journal of Operational Research, vol. 192, no. 1, pp. 1-17, 2009.

[14] J. S. Liu, L. Y. Y. Lu, and W.-M. Lu, "Research fronts in data envelopment analysis," Omega, vol. 58, pp. 33-45, 2016.

[15] J. Aparicio, J. L. Ruiz, and I. Sirvent, "Closest targets and minimum distance to the Pareto-efficient frontier in DEA," Journal of Productivity Analysis, vol. 28, no. 3, pp. 209-218, 2007.

[16] F. Wei, J. Chu, J. Song, and F. Yang, "A cross-bargaining game approach for direction selection in the directional distance function,” OR Spectrum, vol. 41, no. 3, pp. 787-807, 2019.

[17] A. Emrouznejad and G.-1. Yang, "A survey and analysis of the first 40 years of scholarly literature in DEA: 1978-2016," SocioEconomic Planning Sciences, vol. 61, pp. 4-8, 2018.

[18] J. Wu, Q. Zhu, J. Chu, H. Liu, and L. Liang, "Measuring energy and environmental efficiency of transportation systems in China based on a parallel DEA approach," Transportation Research Part D: Transport and Environment, vol. 48, pp. 460-472, 2016.

[19] J. Wu, J. Chu, Q. An, J. Sun, and P. Yin, "Resource reallocation and target setting for improving environmental performance of DMUs: an application to regional highway transportation systems in China," Transportation Research Part D: Transport and Environment, vol. 61, pp. 204-216, 2018.

[20] X. Li, F. Li, N. Zhao, and Q. Zhu, "Measuring environmental sustainability performance of freight transportation seaports in C hina: a data envelopment analysis approach based on the closest targets," Expert Systems, vol. 37, no. 4, Article ID e12334, 2018.

[21] J. Ren, B. Gao, J. Zhang, and C. Chen, "Measuring the energy and carbon emission efficiency of regional transportation systems in China: chance-constrained DEA models," Mathematical Problems in Engineering, vol. 2020, Article ID 9740704, 12 pages, 2020.

[22] H. Liu, R. Yang, Y. Wang, and Q. Zhu, "Measuring performance of road transportation industry in China in terms of integrated environmental efficiency in view of streaming data," Science of The Total Environment, vol. 727, Article ID 138675, 2020.

[23] J. L. Ruiz, J. V. Segura, and I. Sirvent, "Benchmarking and target setting with expert preferences: an application to the evaluation of educational performance of Spanish universities," European Journal of Operational Research, vol. 242, no. 2, pp. 594-605, 2015.

[24] L. Fang, "Centralized resource allocation based on efficiency analysis for step-by-step improvement paths," Omega, vol. 51, pp. 24-28, 2015.

[25] G. Egilmez and Y. S. Park, "Transportation related carbon, energy and water footprint analysis of U.S. manufacturing: an eco-efficiency assessment," Transportation Research Part D: Transport and Environment, vol. 32, pp. 143-159, 2014.

[26] M. Beltrán-Esteve and A. J. Picazo-Tadeo, “Assessing environmental performance trends in the transport industry: ecoinnovation or catching-up?" Energy Economics, vol. 51, pp. 570-580, 2015.
[27] R. K. Mavi, A. Fathi, R. F. Saen, and N. K. Mavi, "Eco-innovation in transportation industry: a double frontier common weights analysis with ideal point method for Malmquist productivity index," Resources, Conservation and Recycling, vol. 147, pp. 39-48, 2019.

[28] H. Omrani, K. Shafaat, and A. Alizadeh, "Integrated data envelopment analysis and cooperative game for evaluating energy efficiency of transportation sector: a case of Iran," Annals of Operations Research, vol. 274, no. 1-2, pp. 471-499, 2019.

[29] Q. Cui and Y. Li, "The evaluation of transportation energy efficiency: an application of three-stage virtual frontier DEA," Transportation Research Part D: Transport and Environment, vol. 29, pp. 1-11, 2014.

[30] A. Stefaniec, K. Hosseini, J. Xie, and Y. Li, "Sustainability assessment of inland transportation in China: a triple bottom line-based network DEA approach," Transportation Research Part D: Transport and Environment, vol. 80, p. 102258, 2020.

[31] Q. Zhu, X. Li, F. Li, J. Wu, and D. Zhou, "Energy and environmental efficiency of China's transportation sectors under the constraints of energy consumption and environmental pollutions," Energy Economics, vol. 89, Article ID 104817, 2020.

[32] N. Tian, S. Tang, A. Che, and P. Wu, "Measuring regional transport sustainability using super-efficiency SBM-DEA with weighting preference," Journal of Cleaner Production, vol. 242, p. $118474,2020$.

[33] T. H. Oum, S. Pathomsiri, and Y. Yoshida, "Limitations of DEA-based approach and alternative methods in the measurement and comparison of social efficiency across firms in different transport modes: an empirical study in Japan," Transportation Research Part E: Logistics and Transportation Review, vol. 57, pp. 16-26, 2013.

[34] L. Zhao, Y. Zhao, Q. Hu, H. Li, and J. Stoeter, "Evaluation of consolidation center cargo capacity and loctions for China railway express," Transportation Research Part E: Logistics and Transportation Review, vol. 117, pp. 58-81, 2018.

[35] G. Martini, A. Manello, and D. Scotti, “The influence of fleet mix, ownership and LCCs on airports' technical/environmental efficiency," Transportation Research Part E: Logistics and Transportation Review, vol. 50, pp. 37-52, 2013.

[36] A. Voltes-Dorta and J. C. Martín, "Benchmarking the noiseoriented efficiency of major European airports: a directional distance function approach," Transportation Research Part E: Logistics and Transportation Review, vol. 91, pp. 259-273, 2016.

[37] W. Lu, S. H. Park, T. Huang, and G. T. Yeo, “An analysis for Chinese airport efficiency using weighted variables and adopting CFPR," The Asian Journal of Shipping and Logistics, vol. 35, no. 4, pp. 230-242, 2019.

[38] M. Song, G. Jia, and P. Zhang, "An evaluation of air transport sector operational efficiency in China based on a three-stage DEA analysis," Sustainability, vol. 12, no. 10, p. 4220, 2020.

[39] M. Song, G. Zhang, W. Zeng, J. Liu, and K. Fang, "Railway transportation and environmental efficiency in China," Transportation Research Part D: Transport and Environment, vol. 48, pp. 488-498, 2016.

[40] J. Wu, J. Liu, and D. Guo, "Coastal ports efficiency evaluation and analysis when considering undesirable output," International Journal of Information and Decision Sciences, vol. 9, no. 1, pp. 27-44, 2017.

[41] W. Briec, "Hölder distance function and measurement of technical efficiency," Journal of Productivity Analysis, vol. 11, no. 2, pp. 111-131, 1999. 
[42] F. X. Frei and P. T. Harker, "Projections onto efficient frontiers: theoretical and computational extensions to DEA," Journal of Productivity Analysis, vol. 11, no. 3, pp. 275-300, 1999.

[43] A. Amirteimoori and S. Kordrostami, "A Euclidean distancebased measure of efficiency in data envelopment analysis," Optimization, vol. 59, no. 7, pp. 985-996, 2010.

[44] J. Aparicio and J. T. Pastor, "On how to properly calculate the Euclidean distance-based measure in DEA," Optimization, vol. 63 , no. 3, pp. 421-432, 2014a.

[45] J. T. Pastor and J. Aparicio, "The relevance of DEA benchmarking information and the Least-Distance Measure: Comment," Mathematical and Computer Modelling, vol. 52, no. 1-2, pp. 397-399, 2010.

[46] K. Ando, A. Kai, Y. Maeda, and K. Sekitani, "Least distance based inefficiency measures on the Pareto-efficient frontier in DEA," Journal of the Operations Research Society of Japan, vol. 55, no. 1, pp. 73-91, 2012.

[47] J. Aparicio and J. T. Pastor, "Closest targets and strong monotonicity on the strongly efficient frontier in DEA," Omega, vol. 44, pp. 51-57, 2014b.

[48] H. Fukuyama, J. Leth Hougaard, K. Sekitani, and J. Shi, "Efficiency measurement with a non-convex free disposal hull technology," Journal of the Operational Research Society, vol. 67, no. 1, pp. 9-19, 2016.

[49] J. Aparicio, J. M. Cordero, and J. T. Pastor, "The determination of the least distance to the strongly efficient frontier in Data Envelopment Analysis oriented models: modelling and computational aspects," Omega, vol. 71, pp. 1-10, 2017.

[50] Q. An, Z. Pang, H. Chen, and L. Liang, "Closest targets in environmental efficiency evaluation based on enhanced Russell measure," Ecological Indicators, vol. 51, pp. 59-66, 2015.

[51] S. Razipour-GhalehJough, F. H. Lotfi, G. Jahanshahloo, M. Rostamy-Malkhalifeh, and H. Sharafi, "Finding closest target for bank branches in the presence of weight restrictions using data envelopment analysis," Annals of Operations Research, pp. 1-33, 2019.

[52] P. Zhou, B. W. Ang, and H. Wang, "Energy and CO2 emission performance in electricity generation: a non-radial directional distance function approach," European Journal of Operational Research, vol. 221, no. 3, pp. 625-635, 2012.

[53] N. Zhang and Y. Choi, "A note on the evolution of directional distance function and its development in energy and environmental studies 1997-2013," Renewable and Sustainable Energy Reviews, vol. 33, pp. 50-59, 2014.

[54] K. Tone, "Dealing with undesirable outputs in DEA: a slacksbased measure (SBM) approach," in Proceedings of the Presentation at NAPW III, pp. 44-45, Toronto, Canda, 2004.

[55] W. W. Cooper, L. M. Seiford, and K. Tone, Data Envelopment Analysis: A Comprehensive Text with Models, Applications, References and DEA-Solver Software, Springer, New York, NY, USA, 2nd edition, 2007.

[56] L. Cecchini, S. Venanzi, A. Pierri, and M. Chiorri, "Environmental efficiency analysis and estimation of $\mathrm{CO} 2$ abatement costs in dairy cattle farms in Umbria (Italy): a SBM-DEA model with undesirable output," Journal of Cleaner Production, vol. 197, pp. 895-907, 2018.

[57] J. Wang, S. Wang, S. Li, and K. Feng, "Coupling analysis of urbanization and energy-environment efficiency: evidence from Guangdong province," Applied Energy, vol. 254, p. 113650, 2019.
[58] L. M. Seiford and J. Zhu, "Context-dependent data envelopment analysis-Measuring attractiveness and progress," Omega, vol. 31, no. 5, pp. 397-408, 2003.

[59] IPCC: 2006 IPCC Guidelines for National Greenhouse Gas Inventories, 2006, https://www.ipcc-nggip.iges.or.jp/public/ 2006gl/index.html. 